\title{
Effect of Multiple Hole Distribution and Shape Based on Particle Flow on Rocklike Failure Characteristics and Mechanical Behavior
}

\author{
Zhiguo Xia $\mathbb{D}^{1},{ }^{1}$ Ning Jiang $\mathbb{D}^{1},{ }^{1}$ Huisan Yang, ${ }^{1}$ Liu Han, ${ }^{2}$ Haiyang Pan, ${ }^{1,3}$ Zhenhua Zhao, ${ }^{2}$ \\ and Quanlin Feng ${ }^{2}$ \\ ${ }^{1}$ State Key Laboratory of Mine Disaster Prevention and Control, Shandong University of Science and Technology, \\ Qingdao 266590, China \\ ${ }^{2}$ Shandong Provincial Geo-Mineral Engineering Exploration Institute, Jinan 250014, China \\ ${ }^{3}$ General Institute of Exploration and Research of China National Administration of Coal Geology, Beijing 10039, China
}

Correspondence should be addressed to Ning Jiang; jiangning@sdust.edu.cn

Received 27 August 2020; Revised 24 September 2020; Accepted 25 September 2020; Published 14 October 2020

Academic Editor: Chun Zhu

Copyright ( $) 2020$ Zhiguo Xia et al. This is an open access article distributed under the Creative Commons Attribution License, which permits unrestricted use, distribution, and reproduction in any medium, provided the original work is properly cited.

Based on the particle flow code, numerical models of vertical and horizontal orientations of holes with different shapes were established, and the effects of preexisting holes with different shapes and arrangement patterns on the mechanical behaviors and failure characteristics of rocklike materials were studied. The evolution trend of the stress field is discussed by taking a circular hole as an example. The results show that the existence of holes reduces the peak stress, peak strain, and elastic modulus of the sample, and different shapes of holes and different arrangement patterns have different effects on the mechanical properties and damage degree of the sample and significantly affect the horizontal orientation model. Before crack formation, the compressive stress and tensile stress concentration areas of each sample are located at the left and right ends and the upper and lower ends of the hole, respectively. After model failure, the compressive stress and tensile stress concentration areas of each sample are relatively scattered. In the vertical orientation model, the middle area of vertical holes is the main compressive stress concentration area, which is approximately "columnar" distribution. In the horizontal orientation model, the compressive stress concentration area between the holes is cross distribution and approximately " $\mathrm{X}$ " type distribution. The vertical orientation model sample forms a "columnar" distribution to bear the applied load with a more favorable bearing orientation.

\section{Introduction}

Most natural rock masses have various defect structures such as fractures and holes, affecting the mechanical properties of rocks [1-5]. High tectonic stress exists in the deep rock mass. During the construction of tunnels, reservoirs, mines, and other underground projects, the original stability of rock mass is destroyed, easily leading to instability of rock mass and rock burst, as shown in Figure 1 [5-16]. At the same time, the distribution of internal stress in the rock mass is more complex due to the effect of fracture hole defects [17-22]. Therefore, it is important to study the failure characteristics and mechanical behavior of defective rock mass to understand the instability failure trends of defective rock mass and predict the engineering geological hazards of rock mass.
Many studies have been conducted on the failure characteristics of circular holes and the coalescence mode of cracks, and some meaningful conclusions have been obtained [24-29]. Wong et al. [30] conducted a series of uniaxial compression physical and numerical tests on singlehole specimens with different diameters and widths and studied the splitting failure, failure mode, and strength characteristics caused by crack propagation. Huang et al. [31] studied the strength failure behavior of three noncoplanar circular hole specimens under uniaxial loading using experimental and numerical simulation methods, determined four typical crack coalescence modes, and elucidated the crack evolution mechanism around preexisting holes in granite specimens. Wong and Lin [32] studied crack initiation, coalescence mechanism, and failure behavior of 


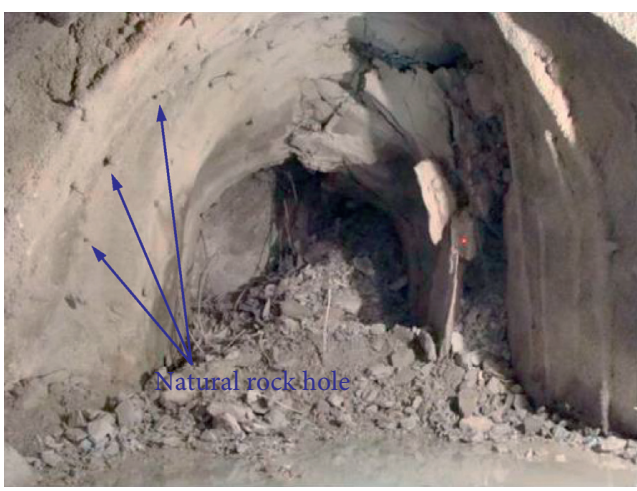

(a)

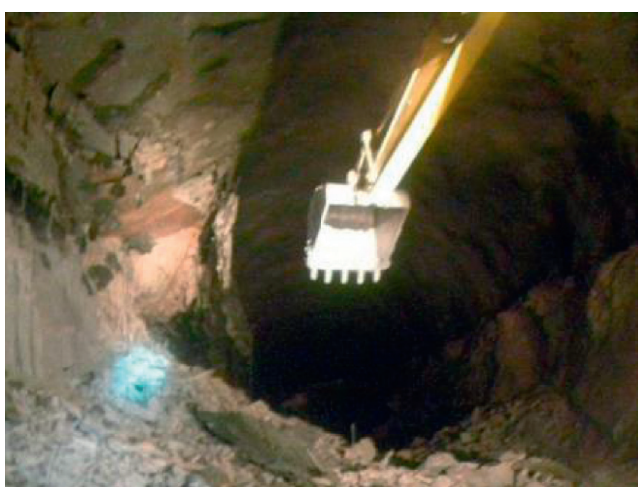

(b)

Figure 1: Rock bursts in tunnel excavation [23]. (a) Rock bursts at tunnel heading. (b) Rock mass collapse at $100 \mathrm{~m}$ from tunnel heading.

granite materials with multiple circular holes under uniaxial compression by physical and numerical experiments, respectively, and proposed a coalescence mechanism criterion related to circular hole distribution. Zhang et al. [33] studied the crack propagation characteristics of rocks around pressure relief drilling with different numbers and different arrangement patterns using experimental methods, studied the unloading effect of three holes with different geometric shapes using FRACOD program, and proposed a new optimization method for pressure relief drilling arrangement parameters.

For hole defects with different shapes, some interesting results have been obtained [34-40]. Li et al. [41] used twodimensional particle flow code (PFC2D) to simulate the failure process of marble containing preexisting holes under uniaxial and biaxial compression conditions and analyzed the effects of preexisting hole shape, confining pressure, and rock heterogeneity on the mechanical properties and crack propagation of marble. Feng et al. [42] studied the failure characteristics and crack propagation of typical hard rock specimens during the unloading of central holes with different shapes using the finite element method (FEM/DEM) and discussed the effect of rock heterogeneity on the strength and range of failure around the central holes of specimens. Raymond and Herbert [43] conducted uniaxial compression tests on prismatic gypsum samples containing one or two inclusions and found that the shear crack propagation degree of samples containing two inclusions at the inclusion boundary significantly increased more than single inclusions. Gui et al. [44] used mixed continuous discrete element method to conduct numerical studies on the effect of circular, rectangular, and triangular holes on rock mechanical behavior, proposed a simulation method that could reasonably reproduce the crack initiation and propagation, and better predicted the mechanical property changes caused by holes.

The above studies were mainly focused on circular holes or single holes with different shapes, while studies on multiple holes with different shapes and different arrangement patterns of multiple holes are scarce. In addition, previous studies mainly focused on the crack propagation and failure modes of rocks containing defects, and relatively few studies were conducted on stress distribution and stress field evolution before crack formation and after crack failure of the sample. However, various types of defective holes exist in the natural rock mass. These defects pose a potential threat to the stability of rock mass. Therefore, PFC2D program was used in this study to establish vertical and horizontal orientation models containing four types of holes with different shapes, studied the effect of hole shape and arrangement on the failure characteristics and mechanical properties of samples, and analyzed the evolution of the stress field in a circular hole model.

\section{Model Design and Determination of Microparameters}

2.1. Particle Flow Code. Particle flow theory was proposed by Cundall and Strack using the discrete element method [45]. Rigid particles are usually used to characterize the rock materials in particle flow code (PFC). The force and displacement between particles are achieved through contact. Among them, the contact bond (CB) and parallel bond (PB) can be used to simulate the connection between rock particles; the $\mathrm{PB}$ not only transfers force but also transfers moment [46-48]. In this study, a uniaxial compression model of a specimen with hole defects was established using the parallel bonding method.

2.2. Determination of Microparameters. When PFC2D is used for a numerical simulation test, the microscopic parameters of particles are important [49]. In this paper, the microscopic parameters were repeatedly adjusted through "trial and error" until the microscopic parameters satisfied the requirements of simulation analysis. The "trial and error" parameter check process of PFC model is shown in Figure 2. The parameter of mi is the Hoek-Brown strength parameter.

A Shimadzu AG-X250 precision universal testing machine was used as the loading system. The universal testing machine possesses good reliability and high precision, and it can be used to perform regular compression and tensile tests. The displacement-based loading control method was used to perform the uniaxial compression test until the sample was 


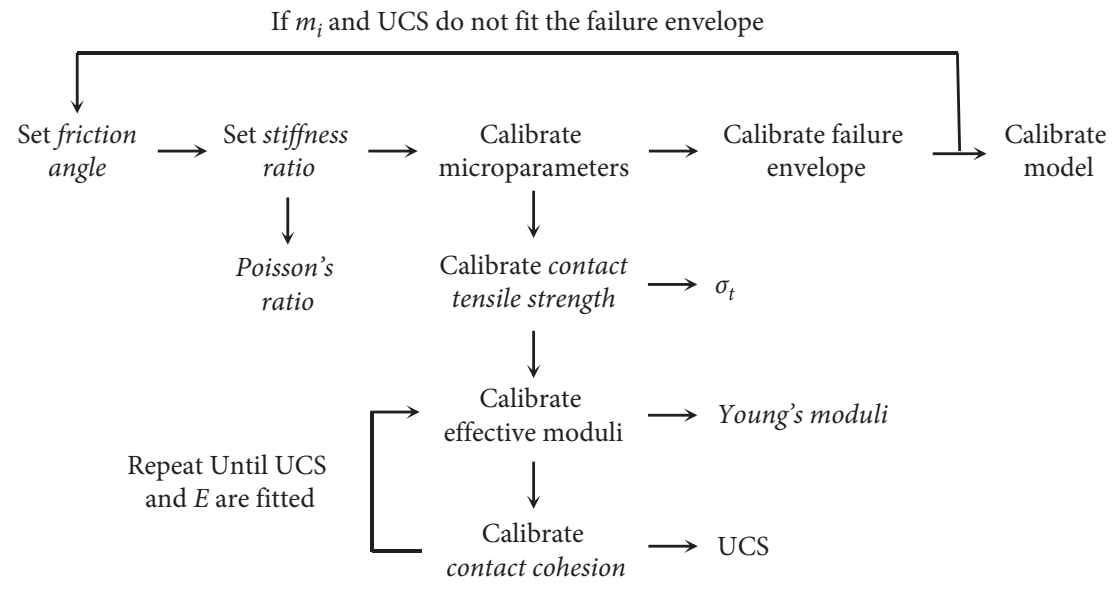

Figure 2: Uniaxial compression calibration procedure defined.

broken. The loading rate was set to $0.01 \mathrm{~mm} / \mathrm{s}$. The numerical model is loaded by displacement loading, and the loading rate is $0.01 / \mathrm{s}$. Based on laboratory tests, PFC2D software was used to check microscopic parameters by trial and error. The parameter check results are shown in Figure 3. The peak strength and elastic modulus of the test sample and numerical sample are basically the same. Although the peak strains of the two samples are different, they are both within the acceptable range. Table 1 shows the micromechanics parameters based on PFC.

2.3. Establishment of the Numerical Model. To study the effect of multiple holes with different shapes on the failure and mechanical behavior of samples, two types of hole models in vertical orientation and horizontal orientation were established. Each type of model had four types of samples with holes of different shapes, and each sample contained seven holes. These two types of models were called the vertical orientation model and horizontal orientation model. The hole shapes of vertical and horizontal orientation models were circular, elliptical, square, and equilateral triangle; the areas of the holes of four shapes were equal; and eight models were established. A schematic diagram of the model is shown in Figure 4(a). The model is $100 \mathrm{~mm}$ high and $100 \mathrm{~mm}$ wide. The area of each hole is about $126.5 \mathrm{~mm}^{2}$. The distance between the midpoint of the hole at the center of the model and the midpoint of the surrounding hole is $25.4 \mathrm{~mm}$. The diameter of the circular hole is $12.7 \mathrm{~mm}$. The major axis of the elliptical hole is $18 \mathrm{~mm}$, and the minor axis is $9 \mathrm{~mm}$. The side length of the equilateral triangle is $17.1 \mathrm{~mm}$. The side length of the square is $12.5 \mathrm{~mm}$. Specific dimensions of the four hole shapes are shown in Figure 4(b). According to the size and location of holes in the model, the particles of holes were deleted, and a numerical model was established as shown in Figure 5.

\section{Test Results}

3.1. Mechanical Properties of Samples. The stress-strain curves and crack number-strain curves of intact rock and defective sample are shown in Figure 6. As shown in
Figure 6(a), the peak strength, peak strain, and elastic modulus of the complete sample are $9.51 \mathrm{MPa}, 0.0082$, and $1.32 \mathrm{GPa}$, respectively. The crack development had three stages, namely, no crack formation, slow crack growth, and fast crack growth, and the stress-strain curve and crack number-strain curve are relatively smooth. Compared with the complete sample, the stress-strain curve of the defective sample fluctuates before and after the peak value. The stressstrain of each sample is different, and crack development is relatively smooth, as shown in Figure 6(b). This is mainly because of the existence of hole defects and different arrangements of holes, varying the original geometric structure of the sample and reducing its bearing capacity. The strain and peak strain at the initial occurrence of a crack in the defective sample are less than those of the intact sample, indicating that the initial crack development and final failure of the defective sample are earlier than those of the complete sample.

A comparison chart of the mechanical properties of the vertical orientation model, horizontal orientation model, and complete sample is shown in Figure 7. The peak stress, peak strain, and elastic modulus of the vertical orientation model and horizontal orientation model are all smaller than those of the complete sample, while the peak stress, peak strain, and elastic modulus of the vertical orientation model are all larger than those of the horizontal orientation model. In the vertical orientation model and horizontal orientation model, there is no obvious trend of peak stress and peak strain from the elliptical sample, triangular sample, and square sample to circular sample, but the elastic modulus gradually increases. Compared with the complete sample, the peak stress and peak strain of the elliptical sample and triangular sample in the vertical orientation model and horizontal orientation model decrease the most, by $63.4 \%$, $35.7 \%$ and $65.5 \%, 41.5 \%, 49.4 \%, 26.3 \%$ and $65.9 \%, 45.1 \%$, respectively, while those of the circular sample decrease the least, by $43.3 \%, 21.6 \%$ and $56.2 \%, 35.4 \%$, respectively. The difference in peak stress, peak strain, and elastic modulus between the vertical orientation model and horizontal orientation model is at most $12.72 \%, 18.66 \%$, and $5.29 \%$, respectively, and at least $2.1 \%, 5.7 \%$, and $0.6 \%$, respectively. 

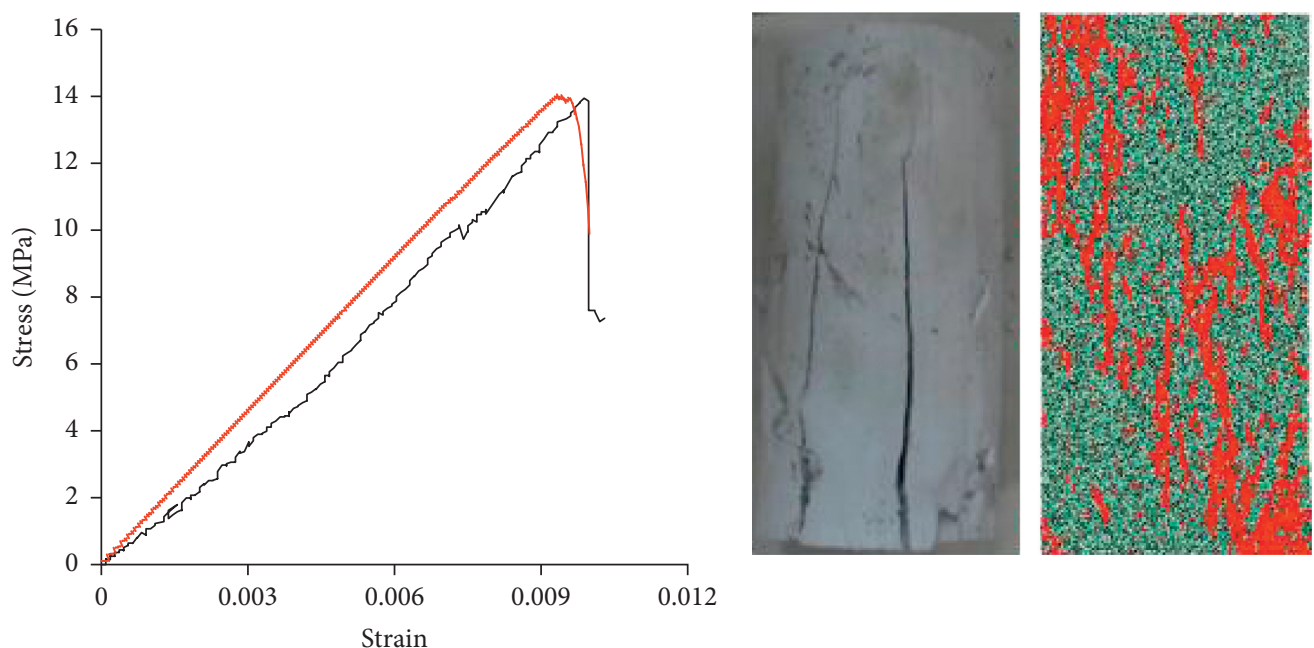

Experimental result

Numerical result

(a)

(b)

Figure 3: Numerical simulation parameter check.

TABLe 1: Micromechanics parameters based on PFC.

\begin{tabular}{lc}
\hline Parameter & Value \\
\hline Minimum particle diameter $(\mathrm{mm})$ & 0.3 \\
Particle diameter ratio & 1.6 \\
Density $\left(\mathrm{kg} / \mathrm{m}^{3}\right)$ & 1470 \\
Contact modulus of the particle $(\mathrm{GPa})$ & 1.32 \\
$\mathrm{CB}$ gap $(\mathrm{mm})$ & 0.05 \\
Normal critical damping ratio & 0.5 \\
Porosity & 0.1 \\
PB friction angle $\left(^{\circ}\right)$ & 35 \\
PB tensile strength $(\mathrm{MPa})$ & 3.5 \\
PB cohesive force $(\mathrm{MPa})$ & 6.3 \\
\hline
\end{tabular}

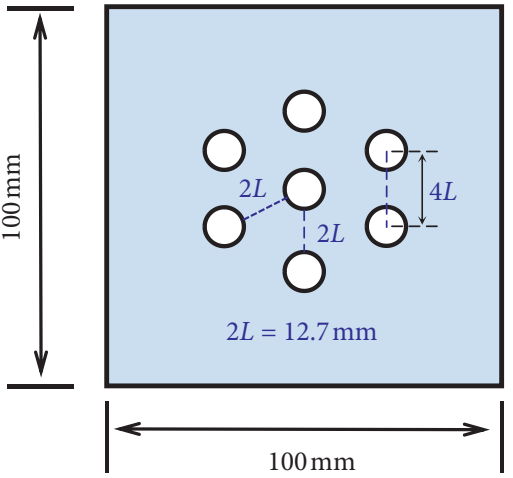

(a)

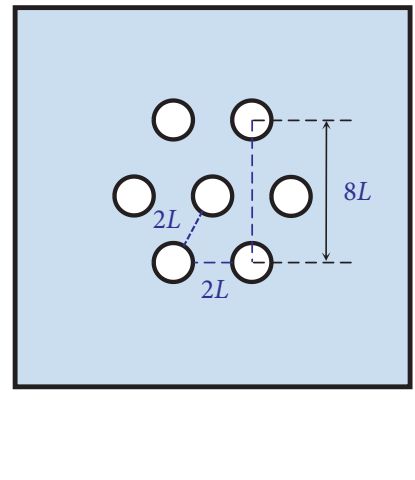

(b)

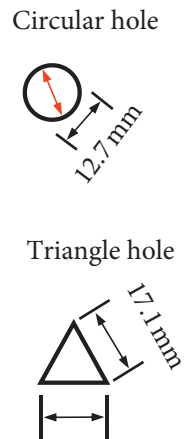

$17.1 \mathrm{~mm}$

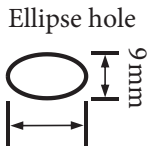

$18 \mathrm{~mm}$

Square hole

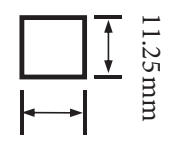

$11.25 \mathrm{~mm}$

(c)

Figure 4: Macropore orientations. (a) Vertical orientation. (b) Horizontal orientation. (c) Hole size.

3.2. Crack Propagation, Evolution, and Failure Characteristics. The final failure diagram of each model and the total number of cracks after model failure are shown in Figures 8 and 9. In the vertical orientation model, the cracks generated at the end of sample hole coalesce each other along the direction of about $60^{\circ}$. In the horizontal orientation model, the cracks generated at the end of sample hole coalesce in different degrees along the directions of about $90^{\circ}$ 

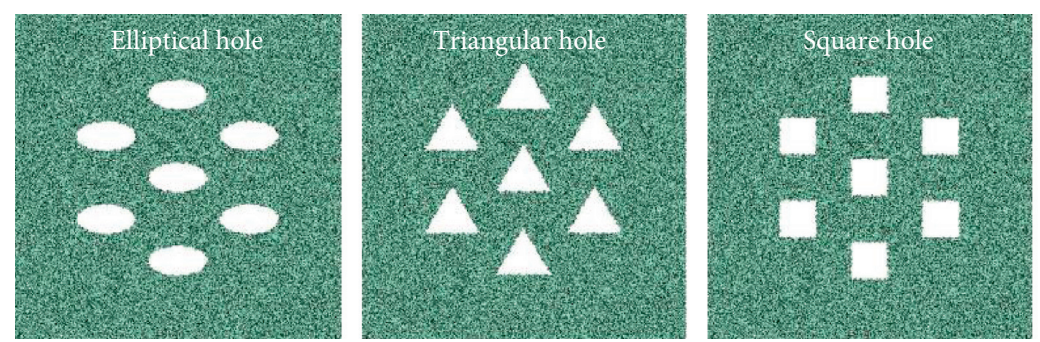

(a)
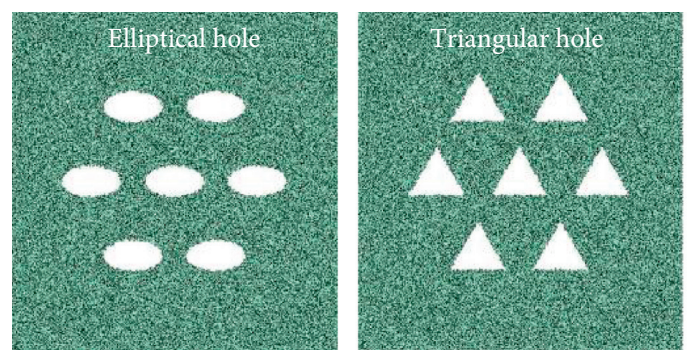
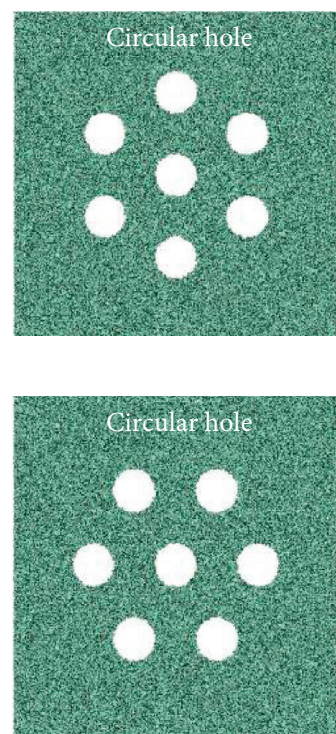

(b)

Figure 5: Numerical model. (a) Vertical orientation model. (b) Horizontal orientation model.

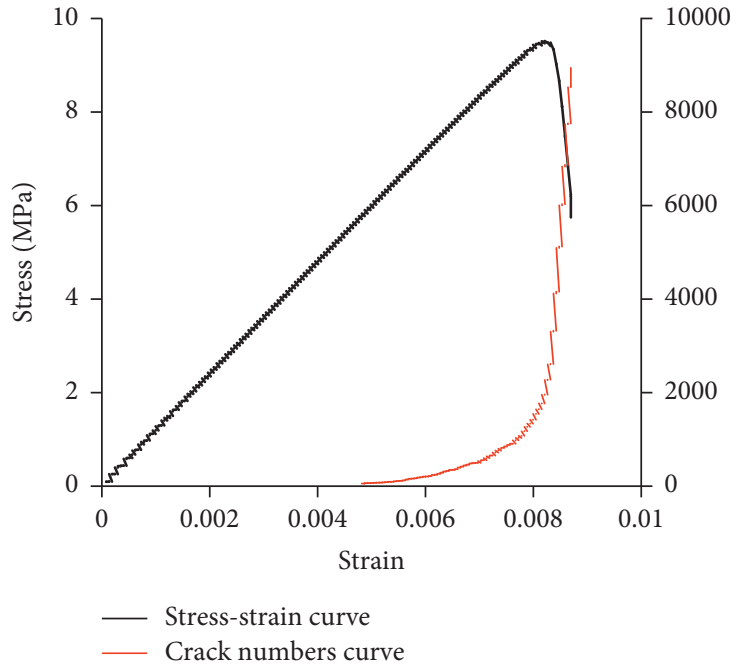

(a)

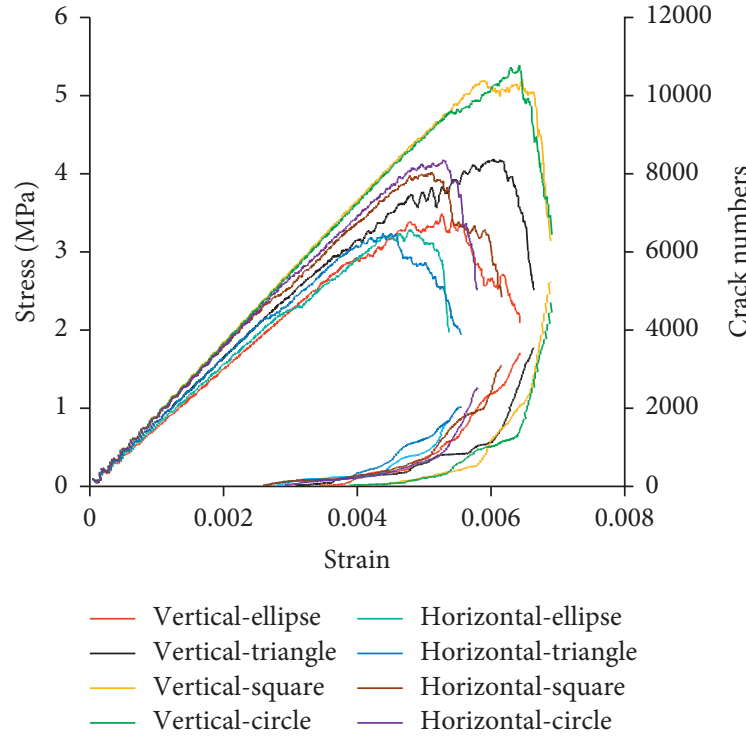

(b)

FiguRE 6: Stress-strain curve and crack number-strain curve of intact rock and rock holes with different shapes. (a) Intact rock. (b) Rock holes with different shapes.

and $0^{\circ}$ in the vertical orientation and horizontal orientation, respectively. In particular, it should be noted that the partial cracks generated in the triangular defect model coalesce along a direction of about $60^{\circ}$. This is mainly due to the fact that the different shapes and arrangement patterns of defects affect the direction and degree of crack growth. When axial load acts on the sample, the stress distribution state inside the sample is changed, thus changing the propagation path of crack. This indicates that the initial development position and propagation trend of the crack are influenced by the arrangement pattern of holes and end position.
The number of cracks in the final failure of each sample of the vertical orientation model and horizontal orientation model is less than that of the complete sample, and the number of cracks in each sample of the vertical orientation model is greater than that of the horizontal orientation model, as shown in Figure 9. Therefore, the existence of hole defects reduces the damage degree of the model, and the damage degree of the horizontal orientation model is larger than that of the vertical orientation model. According to the final development degree of cracks when the two models in Figure 8 are damaged, it can be found that elliptical holes are 


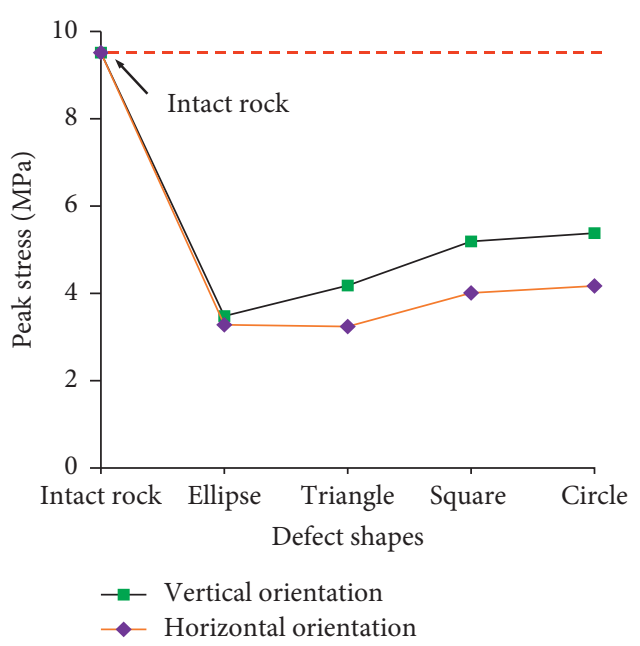

(a)

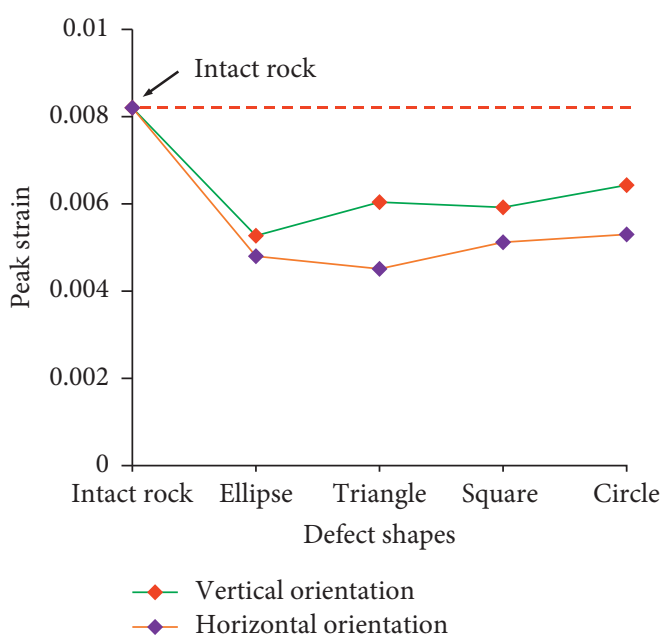

(b)

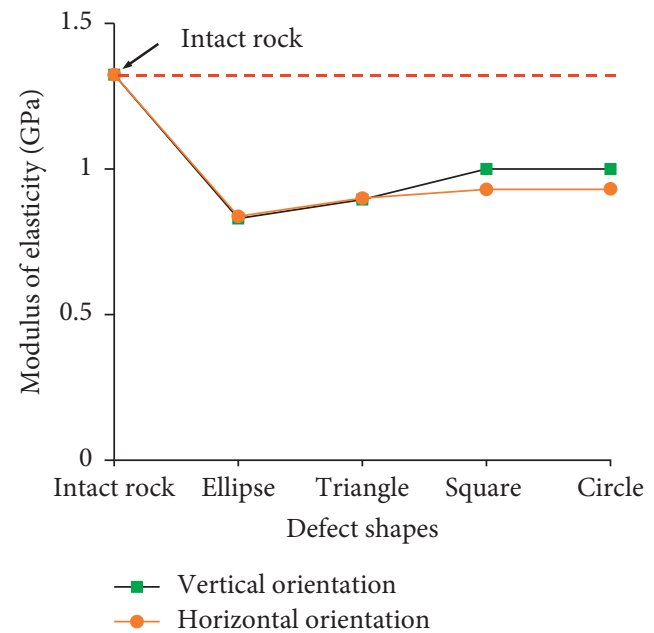

(c)

Figure 7: Mechanical properties of vertical orientation and horizontal orientation models. (a) Peak stress. (b) Peak strain. (c) Elastic modulus.

the least damaged, square holes are the most damaged, and the areas with more severe damage are located at the boundary of both sides of the model. Tensile failure mainly occurs in the area near the hole in the vertical and horizontal orientation models, while shear failure exists between the hole and edge of the sample. Tensile failure dominates in both models, consistent with Colleen et al.

\subsection{Contact Force Distribution before Crack Formation and} after Model Failure. The contact force distribution before crack formation and after crack failure of the vertical orientation model and horizontal orientation model is shown in Figure 10. Before crack formation, the compressive stress of each sample is mainly concentrated at the left and right ends of the hole, and the tensile stress concentration area is mainly distributed at the upper and lower sides of the hole. Influenced by the vertical arrangement of holes, the two sides of middle vertical holes of each sample in the vertical orientation model are the main compressive stress concentration areas, approximately distributed in a "columnar" shape as shown by the yellow dashed line in Figure 10(a). This area is the main stress area and plays a major supporting role in the model. Because of the difference between the arrangement of holes in the horizontal orientation model and that in the vertical orientation model, the compressive stress concentration areas between the holes are distributed cross, which is approximately " $\mathrm{X}$ " type as shown in Figure 10(b). The compressive stress concentration area at the end of the hole near the left and right boundary of the sample is larger than that at the end of the other holes, indicating that the area near the left and right boundary of the sample also plays a good supporting role for the model. The stress concentration area of each sample is distributed around the hole before crack formation. When the model is damaged, because of the influence of model failure mode, although still compressive stress concentration exists around some holes, the main stress concentration area diffuses around the sample, mainly caused by the influence of model failure mode. 


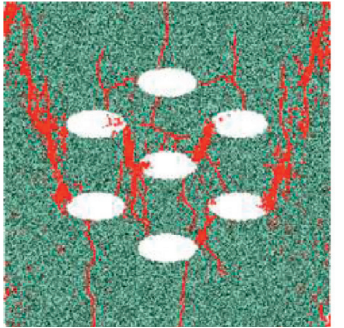

Strain $6.44 / 10^{3}$

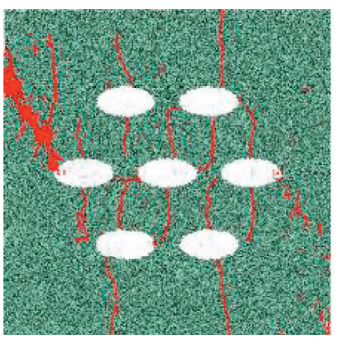

Strain $5.37 / 10^{3}$

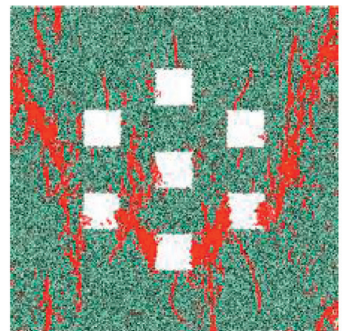

Strain $6.89 / 10^{3}$

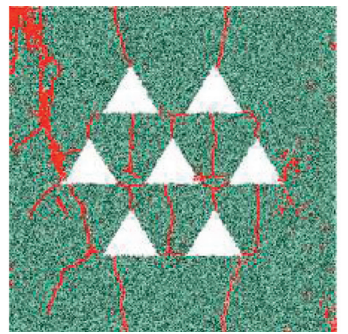

Strain $5.55 / 10^{3}$

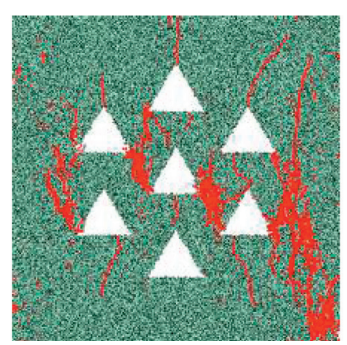

Strain $6.64 / 10^{3}$

(a)

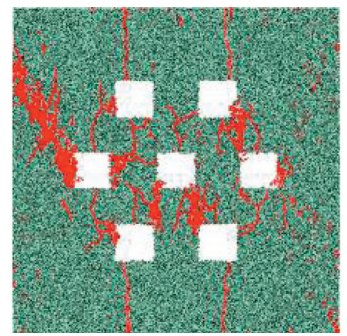

Strain $6.16 / 10^{3}$

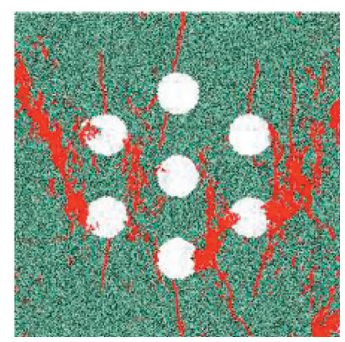

Strain $6.91 / 10^{3}$

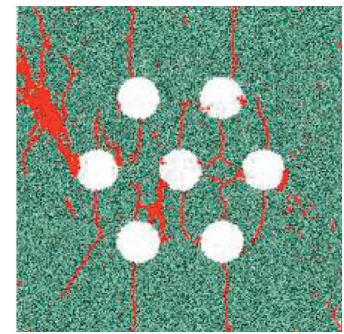

Strain $5.80 / 10^{3}$

(b)

Figure 8: Crack evolution of the (a) vertical orientation model and (b) horizontal orientation model.

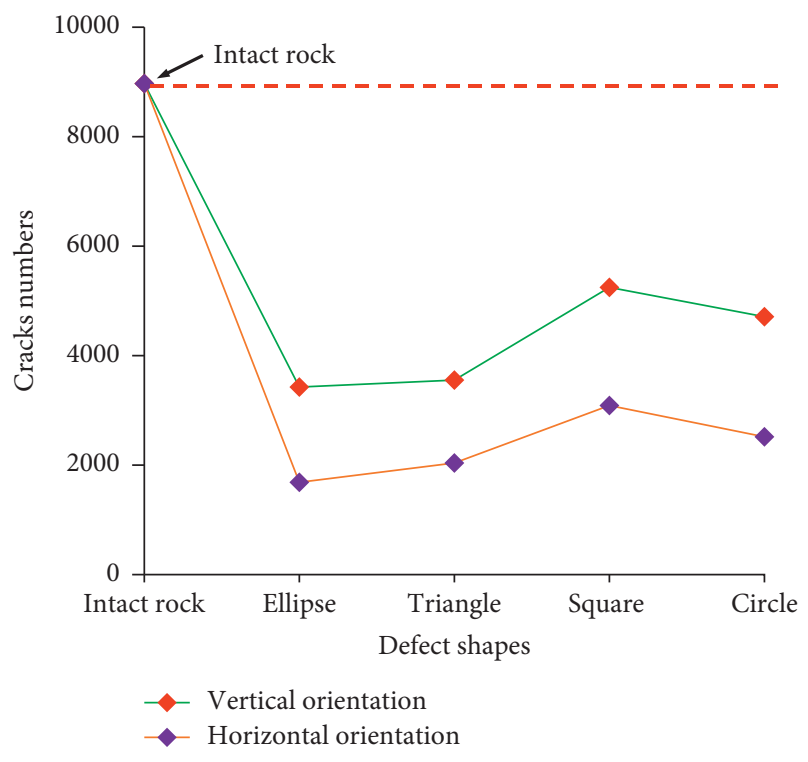

FIGURE 9: Total number of cracks after model failure.

3.4. Stress Field Evolution of Circular Holes. Because of a large number of established model samples and limited space, more common circular hole samples (circular hole samples of vertical and horizontal orientation models) were selected in this study as the research object to analyze the stress field evolution. Figure 11 shows the stress field evolution nephogram of circular holes (where the blue area is the main compressive stress concentration area, the red area is the main tensile stress concentration area, the tensile stress is positive, and the compressive stress is negative).
In the vertical orientation model, before the crack is initially generated, that is, when the strain is $0.368 \times 10^{-3}$, the compressive stress and tensile stress concentration at the left and right ends and the upper and lower ends of the hole are obvious, respectively, and the stress decreases significantly near the tensile stress concentration area. With continuous loading, the compressive stress concentration range, tensile stress concentration range, and stress decreasing zone at both ends of the hole increase. When the strain is $5.55 \times 10^{-3}$, affected by crack propagation, the compressive stress concentration area shifts to the left and right boundaries of the model. When the strain is $6.66 \times 10^{-3}$, the model failure is further intensified, the range of compressive stress concentration is relatively dispersed, and the compressive stress concentration areas near the left and right ends of two circular holes on the right side disappear, mainly due to the release of stress caused by the propagation of cracks. When the model runs to 0.6 times of the peak stress (strain is $6.91 \times 10^{-3}$ ), although the model failure is relatively severe, still a compressive stress concentration exists between the two rows of elliptical holes, and the maximum compressive stress reaches $18 \mathrm{MPa}$ at this time, still playing a supporting role on the model consistent with the distribution of contact force shown in Figure 10(a). In the horizontal orientation model, the distribution positions of compressive stress concentration area and tensile stress concentration area are the same as those in the vertical orientation model, located at the left and right ends and the upper and lower ends of holes, respectively, but the stress concentration range is relatively scattered, mainly affected by the hole arrangement patterns and vertical and horizontal spacing between the two holes. With continuous loading, the compressive stress concentration range first increases and then decreases, while the 

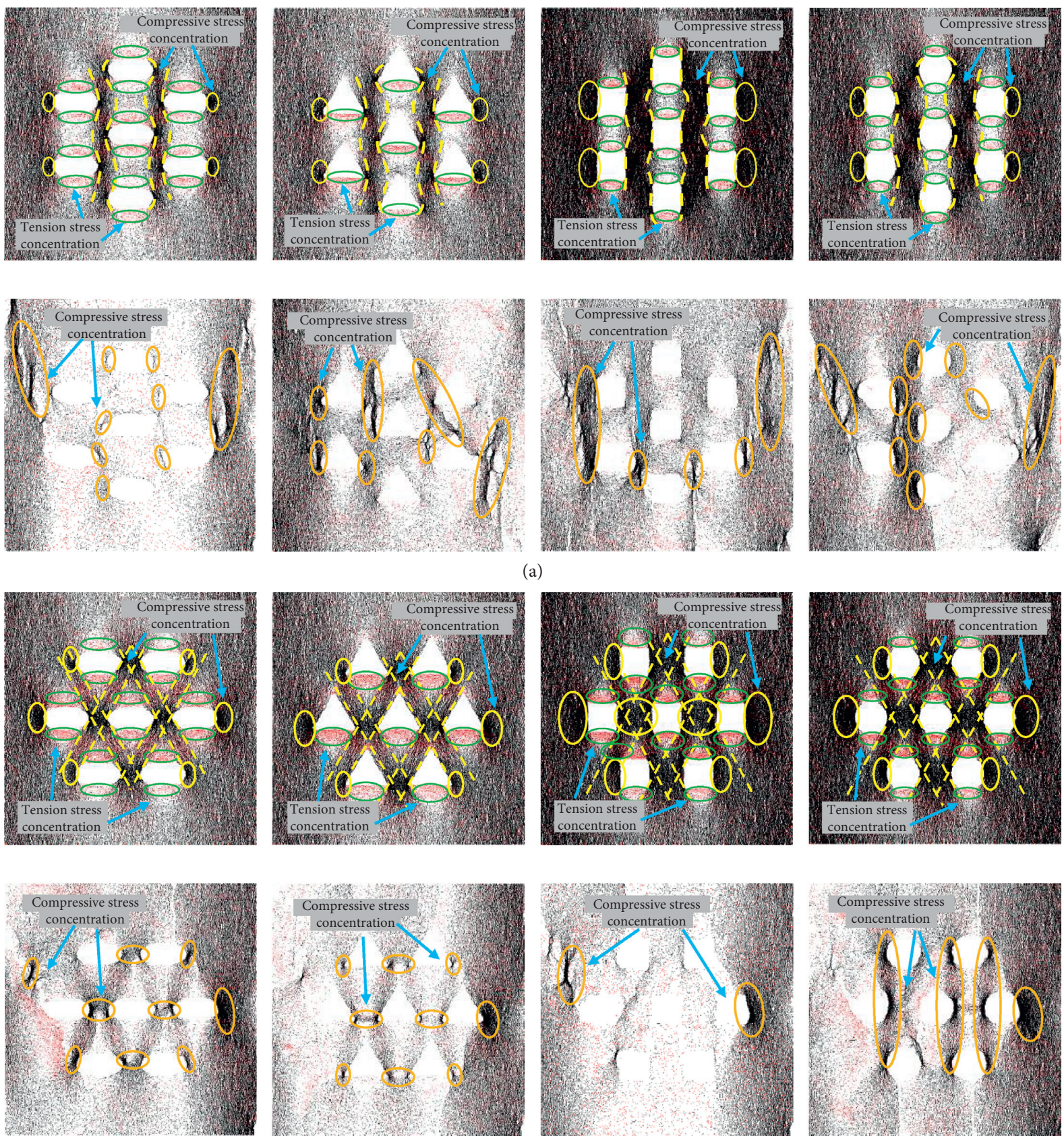

(b)

FIGURE 10: Distribution of contact forces before crack formation and after crack failure in vertical and horizontal orientation models (the black lines represent compressive stress. The red lines represent tensile stress. The dense and sparse lines represent the magnitude of stress. The yellow ellipse and yellow curve marked areas are compressive stress concentration areas, and the green ellipse marked areas are tensile stress concentration areas). (a) Contact force before crack formation and after crack failure of the vertical orientation model. (b) Contact force before crack formation and after crack failure of the horizontal orientation model.

tensile stress concentration range increases all the time. However, still a high compressive stress concentration exists in the area between the holes in the vertical orientation, supporting the model. From the stress distribution nephogram of the vertical orientation model and horizontal orientation model, it can be observed that the arrangement pattern of holes significantly affects the stress field distribution of the model.
To further understand the failure mechanism of rock with holes, the stress distribution around circular holes under uniaxial compressive stress was calculated according to the elastic mechanics theory and the famous Kirsch analytical solution [50]. Kirsch's analytical solution is shown in equation (1), where $\sigma_{r}$ $\sigma_{\theta}$, and $\tau_{r \theta}$ are radial, tangential, and shear stresses, respectively. $p$ and $q$ are vertical and horizontal stresses, respectively. $\theta$ is the angle between the horizontal axis and radius: 


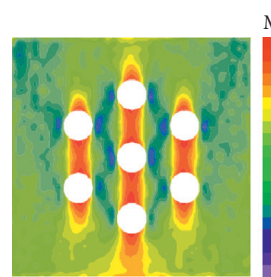

Strain $0.368 / 10^{3}$

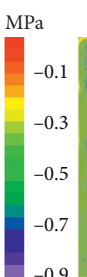

$-0.9$

Strain $4.44 / 10^{3}$

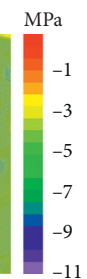

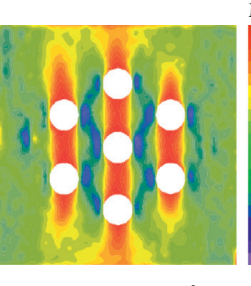

Strain $5.55 / 10^{3}$

(a)

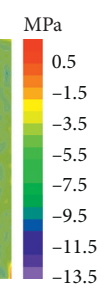

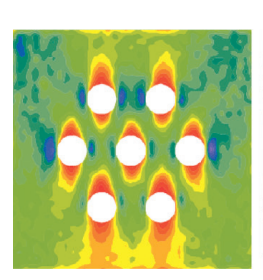

Strain $0.368 / 10^{3}$

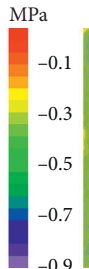

$-0.9$

Strain $3.24 / 10^{3}$

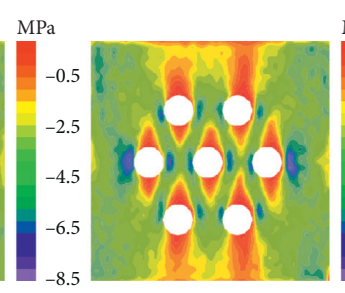

Strain $4.35 / 10^{3}$

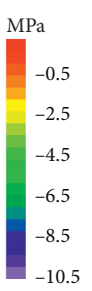

(b)

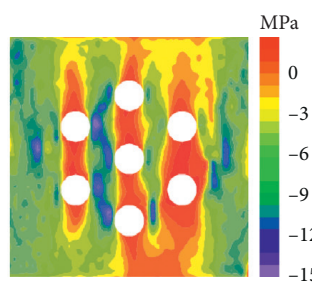

Strain $6.66 / 10^{3}$

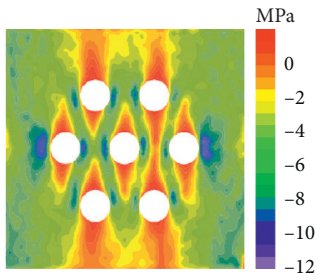

Strain $4.90 / 10^{3}$

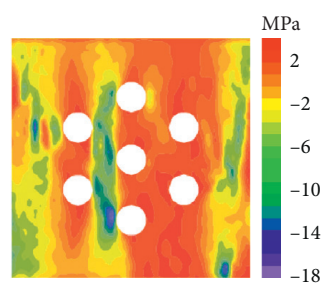

Strain $6.91 / 10^{3}$

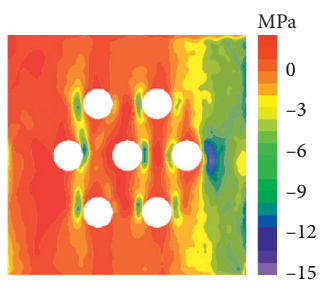

Strain $5.80 / 10^{3}$

FigURE 11: Evolution of stress fields in vertical and horizontal orientations of circular holes. (a) Evolution of vertical orientation stress field. (b) Evolution of horizontal orientation stress field.

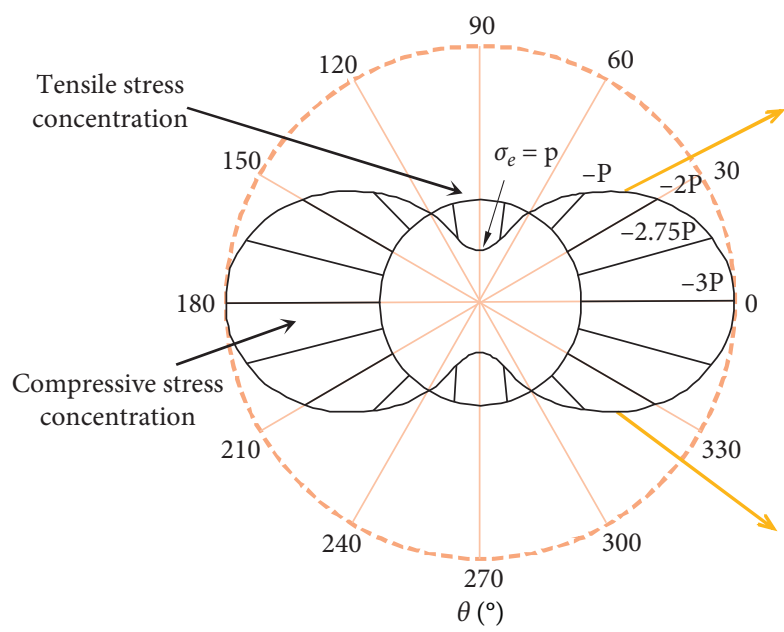

(a)
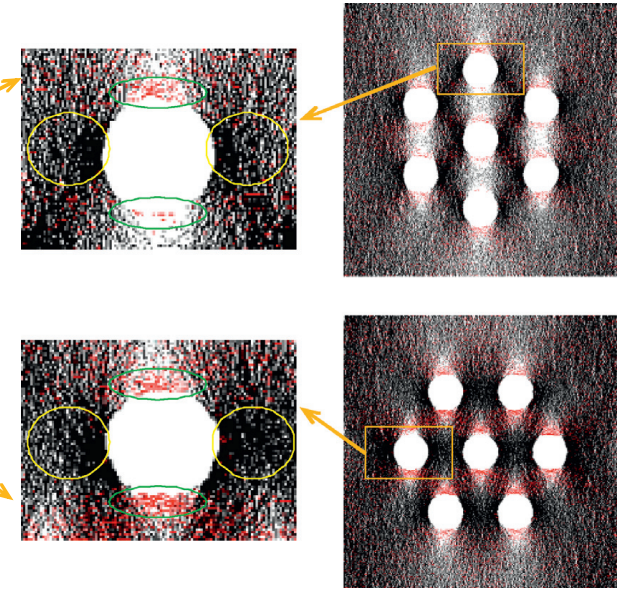

(b)

FIgURE 12: Distribution of tangential stress around a circular hole under uniaxial compression.

$$
\begin{aligned}
\sigma_{r} & =\frac{p+q}{2}\left(1-\frac{L^{2}}{r^{2}}\right)+\frac{q-p}{2}\left(1-4 \frac{L^{2}}{r^{2}}+3 \frac{L^{4}}{r^{4}}\right) \cos 2 \theta, \\
\sigma_{\theta} & =\frac{p+q}{2}\left(1+\frac{L^{2}}{r^{2}}\right)-\frac{q-p}{2}\left(1+3 \frac{L^{4}}{r^{4}}\right) \cos 2 \theta, \\
\tau_{r \theta} & =\frac{q-p}{2}\left(1+2 \frac{L^{2}}{r^{2}}-3 \frac{L^{4}}{r^{4}}\right) \sin 2 \theta .
\end{aligned}
$$

In this study, the radius of the circular hole under uniaxial compressive stress $r=L$, and the horizontal force $q=0$. Thus, equation (1) can be converted into

$$
\begin{aligned}
\sigma_{r} & =\tau_{r \theta}=0, \\
\sigma_{\theta} & =p(1+2 \cos 2 \theta) .
\end{aligned}
$$

The tangential stress distribution at the boundary of the circular hole under uniaxial compressive stress [51] is shown in Figure 12(a). Tensile stress concentration areas are formed at the top and bottom of the circular hole, and compressive stress concentration areas are formed at the left and right ends of the circular hole. This is consistent with the studies of compressive stress and tensile stress distribution in Section 3.3 of this paper.

$\sigma_{\theta}$ and $p$ are the tangential stress and vertical stress, respectively. $\theta$ is the polar angle between the horizontal axis and polar radius, $r$. The tangential stress along the contour of 


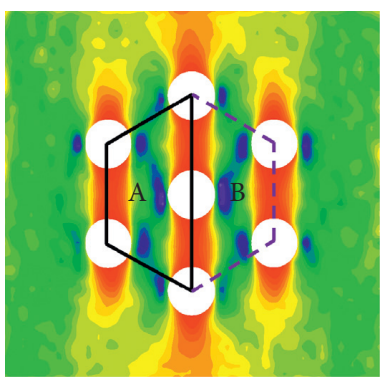

(a)

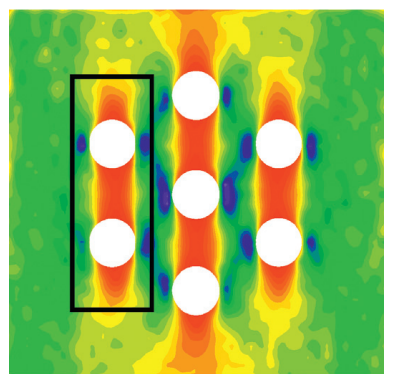

(e)

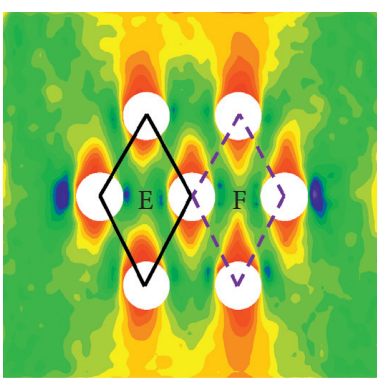

(b)

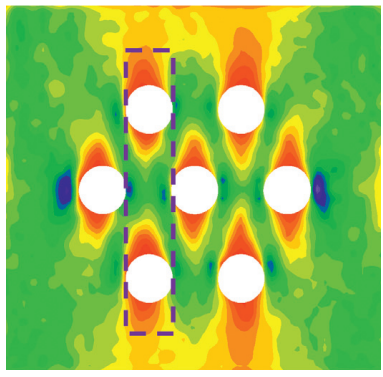

(f)

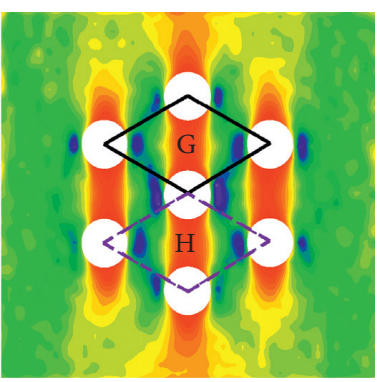

(c)

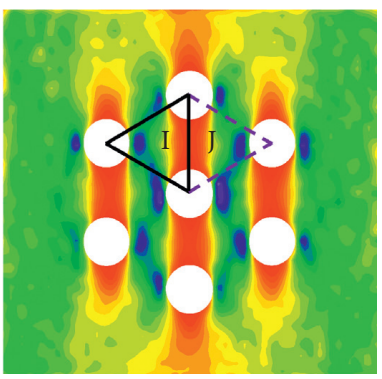

(g)

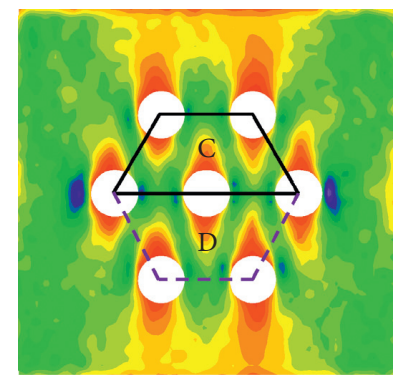

(d)

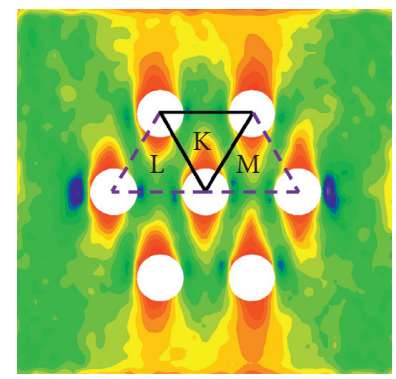

(h)

FIgURE 13: Decomposition diagram of hole combination (in the figure, the blue area is the main concentration area of compressive stress, and the red area is the main concentration area of tensile stress).

the hole is represented by the line segment perpendicular to the contour of the hole, with the length of line segment indicating the relative magnitude of local principal stress. The line segment is positive when it lies outside the hole contour and vice versa.

According to the distribution of stress field in the circular hole model, the existence of holes causes compressive stress, tensile stress concentration area, and stress decreasing zone to appear around the holes, and the existence of regular holes can make the distribution of these stress concentration areas and decreasing zones more regular. This provides ideas for predicting and changing the stress magnitude and location of a certain area in engineering construction.

The vertical and horizontal orientations of circular holes are taken as examples for simple analysis. To illustrate that stress distribution might be affected by the stress direction of the model, the spacing between holes, and the arrangement pattern of holes, the circular hole combination is decomposed, as shown in Figure 13, and the marked $\mathrm{A}$ and $\mathrm{B}$ areas in the figure are symmetrical areas. Figures 13(a) and 13(d), 13(b), and 13(c) have the same geometric figures in areas A, B and C, D, E, F and G, H, I, J and L, M, which are isosceles trapezoids and parallelograms, respectively, with equal areas. Because the loading method used in this study is axial loading, the geometric edges of external forces in Figures 13(a) and 13(d), 13(b), and $13(\mathrm{c})$ are different, resulting in different distributions of internal stress. This indicates that stress direction affects the stress distribution of the hole model. In Figure 13(e), the area between two circular holes encircled by the rectangle is mainly tensile stress and stress decreasing zone. In Figure 13(f), the upper and lower ends of two holes encircled by the rectangle also have tensile stress and stress decreasing zone, but the tensile stress area between the two holes does not coalesce and still is dominated by compressive stress. This indicates that hole spacing affects the distribution of stress (although other holes will affect the stress of two holes, they have less influence on the stress in the vertical orientation, and no major analysis will be made). Although the I, J and L, M areas in Figures 13(g) and 13(h) are both geometric triangular areas, the different arrangement patterns of I and J areas in Figure 13(g) and the $\mathrm{L}$ and $\mathrm{M}$ areas in Figure 13(h) result in a large difference of stress distribution between them, indicating that the hole arrangement pattern affects the stress distribution of the model. In addition, the stress distribution of vertical and horizontal orientation models of holes with the same shape also illustrates this point.

In engineering construction, the concentration of high stress may cause rock burst, which might pose a threat to the safety of personnel in engineering construction. This analysis shows that to reduce or transfer stress, according to the general situation of engineering geology, based on the analysis of actual structural stress and in combination with engineering needs, the arrangement pattern, size, and spacing of holes can be designed to satisfy the needs of pressure relief or stress transfer.

\section{Conclusions}

(1) The existence of holes affected the mechanical properties of the sample and reduced the peak stress, peak strain, and elastic modulus of the sample. The effect of holes on the mechanical properties of the horizontal orientation model was greater than that of 
the vertical orientation model; that is, the different arrangement patterns of holes had different influences on the mechanical properties of the sample.

(2) The development and propagation trend of cracks were influenced by the arrangement pattern of holes and the position of their ends. The existence of holes reduced the degree of model failure, and the damage degree of the model in the horizontal orientation decreased more. The damage modes of both models were mainly tensile failure.

(3) The compressive stress and tensile stress concentration areas were located at the left and right ends and the upper and lower ends of the hole, respectively. In the vertical orientation model, the area between the holes in the vertical orientation was the main compressive stress concentration area, which was approximately "columnar" distribution. In the horizontal orientation model, the compressive stress concentration area between the holes is cross distribution and approximately " $\mathrm{X}$ " type distribution.

(4) The arrangement pattern, size, and spacing of holes were important factors that affected the stress distribution of the model, which can provide ideas for predicting and changing the stress magnitude and location of a certain area in engineering construction.

\section{Data Availability}

All data are available within the article and also from the corresponding author upon request.

\section{Conflicts of Interest}

The authors declare that there are no conflicts of interest regarding the publication of this paper.

\section{Acknowledgments}

This work was supported by the National Key R\&D Program (2018YFC0604705); National Natural Science Foundation of China (52004146, 51774194, and 51904167); Shandong Provincial National Science Fund for Distinguished Young Scholars (JQ201612); Taishan Scholar Talent Team Support Plan for Advantaged \& Unique Discipline Areas; SDUST Research Fund (2019TDJH101); and Scientific Research Foundation of Shandong University of Science and Technology for Recruited Talents (2019RCJJ019).

\section{References}

[1] A. Bobet and H. H. Einstein, "Fracture coalescence in rocktype materials under uniaxial and biaxial compression," International Journal of Rock Mechanics and Mining Sciences, vol. 35, no. 7, pp. 863-888, 1998.

[2] Z. Han, D. Li, Q. Zhu, M. Liu, and Z. Sun, "Dynamic fracture evolution and mechanical behavior of sandstone containing noncoplanar elliptical flaws under impact loading," Advances in Civil Engineering, vol. 2018, Article ID 5649357, 16 pages, 2018.
[3] E. Klein and T. Reuschlé, "A pore crack model for the mechanical behaviour of porous granular rocks in the brittle deformation regime," International Journal of Rock Mechanics and Mining Sciences, vol. 41, no. 6, pp. 975-986, 2004.

[4] D. Liu, Z. Gu, R. Liang et al., "Impacts of pore-throat system on fractal characterization of tight sandstones," Geofluids, vol. 2020, Article ID 4941501, 17 pages, 2020.

[5] J. Wang, Y. Zhang, Z. Qin et al., "Analysis method of water inrush for tunnels with damaged water-resisting rock mass based on finite element method-smooth particle hydrodynamics coupling," Computers and Geotechnics, vol. 126, pp. 1-10, 2020.

[6] P. Lin, R. H. C. Wong, and C. A. Tang, "Experimental study of coalescence mechanisms and failure under uniaxial compression of granite containing multiple holes," International Journal of Rock Mechanics and Mining Sciences, vol. 77, pp. 313-327, 2015.

[7] S. J. Chen, D. W. Yin, N. Jiang, F. Wang, and Z. H. Zhao, "Mechanical properties of oil shale-coal composite samples," International Journal of Rock Mechanics and Mining Sciences, vol. 123, pp. 104-120, 2019.

[8] N. Jiang, C. Wang, H. Pan, D. Yin, and J. Ma, "Modeling study on the influence of the strip filling mining sequence on mining-induced failure," Energy Science \& Engineering, vol. 8, no. 6, pp. 2239-2255, 2020.

[9] C. X. Wang, B. T. Shen, J. T. Chen et al., "Compression characteristics of filling gangue and simulation of mining with gangue backfilling: an experimental investigation," Geomechanics and Engineering, vol. 20, no. 6, pp. 485-495, 2020.

[10] J. T. Chen, J. H. Zhao, S. C. Zhang, Y. Zhang, F. Yang, and M. Li, "An experimental and analytical research on the evolution of mining cracks in deep floor rock mass," Pure and Applied Geophysics, 2020.

[11] D. Ren, D. Zhou, D. Liu, F. Dong, S. Ma, and H. Huang, "Formation mechanism of the upper triassic Yanchang formation tight sandstone reservoir in Ordos Basin-take chang 6 reservoir in Jiyuan oil field as an example," Journal of Petroleum Science and Engineering, vol. 178, pp. 497-505, 2019.

[12] J. Xu, A. Haque, W. Gong et al., "Experimental study on the bearing mechanisms of rock-socketed piles in soft rock based on micro X-ray CT analysis," Rock Mechanics and Rock Engineering, vol. 53, no. 8, pp. 3395-3416, 2020.

[13] J. Xu, G. L. Dai, W. M. Gong, Q. Zhang, A. Haque, and R. P. Gamage, "A review of research on the shaft resistance of rock-socketed piles," Acta Geotechnica, vol. 2020, pp. 1-25, 2020.

[14] J. B. Wei, S. M. Wang, Z. Zhao, D. L. Li, and L. P. Guo, "Numerical study of damage to rock surrounding an underground coal roadway excavation," Advances in Civil Engineering, vol. 2020, Article ID 8863289, 16 pages, 2020.

[15] Q. Liu, J. Chai, S. J. Chen, D. D. Zhang, Q. Yuan, and S. Wang, "Monitoring and correction of the stress in an anchor bolt based on pulse pre-pumped Brillouin Optical time domain analysis," Energy Science and Engineering, vol. 8, no. 10, 2020.

[16] Y. Wang, B. Liu, and Y. Qi, "A risk evaluation method with an improved scale for tunnel engineering," Arabian Journal for Science and Engineering, vol. 43, no. 4, pp. 2053-2067, 2018.

[17] J. Zhao, X. Zhang, N. Jiang, L. Yin, and W. Guo, "Porosity zoning characteristics of fault floor under fluid-solid coupling," Bulletin of Engineering Geology and the Environment, vol. 79, no. 5, pp. 2529-2541, 2020.

[18] J. H. Zhao, J. T. Chen, X. G. Zhang, N. Jiang, and Y. Z. Zhang, "Distribution characteristics of floor pore water pressure 
based on similarity simulation experiments," Bulletin of Engineering Geology and the Environment, 2020.

[19] G. Feng, Y. Kang, X. Wang, Y. Hu, and X. Li, "Investigation on the failure characteristics and fracture classification of shale under brazilian test conditions," Rock Mechanics and Rock Engineering, vol. 53, no. 7, pp. 3325-3340, 2020.

[20] G. Feng, X. C. Wang, M. Wang, and Y. Kang, "Experimental investigation of thermal cycling effect on fracture characteristics of granite in a geothermal-energy reservoir," Engineering Fracture Mechanics, vol. 235, pp. 1-16, 2020.

[21] G. C. Shi, X. J. Yang, H. C. Yu et al., "Acoustic emission characteristics of creep fracture evolution in double-fracture fine sandstone under uniaxial compression," Engineering Fracture Mechanics, vol. 210, pp. 13-28, 2018.

[22] F. Ren, C. Zhu, and M. He, "Moment tensor analysis of acoustic emissions for cracking mechanisms during schist strain burst," Rock Mechanics and Rock Engineering, vol. 53, no. 1, pp. 153-170, 2020.

[23] P. Lin, H. Liu, and W. Zhou, "Experimental study on failure behaviour of deep tunnels under high in-situ stresses," Tunnelling and Underground Space Technology, vol. 46, pp. 28-45, 2015.

[24] H. Huang, T. Babadagli, X. Chen et al., "Performance comparison of novel chemical agents for mitigating waterblocking problem in tight gas sandstones," SPE Reservoir Evaluation \& Engineering, vol. 2020, pp. 1-9, 2020.

[25] J. B. Carter, E. Z. Lajtal, and Y. G. Yuan, "Tensile fracture from circular cavities loaded in compression," International Journal of Fracture, vol. 57, pp. 221-236, 1992.

[26] M.-r. Du, H.-w. Jing, H.-j. Su, T.-t. Zhu, and M.-l. Chen, "Strength and failure characteristics of sandstone containing two circular holes filled with two types of inclusions under uniaxial compression," Journal of Central South University, vol. 24, no. 11, pp. 2487-2495, 2017.

[27] J. C. Duan, C. A. Tang, X. Chang, and Q. S. Chen, "Study on mechanics behavior of containing holes in brittle material subjected to uniaxial compression," Rock and Soil Mechanics, vol. 27, no. 8, pp. 1416-1420, 2006.

[28] Z. W. Liu and Y. H. Li, "Experimental investumental on the deformation and crack behavior of rock specimen with A hole undergoing uniaxial compressive load," Engineering $\mathrm{Me}$ chanics, vol. 27, no. 8, pp. 133-139, 2010.

[29] S. Chen, Z. Xia, and F. Feng, "Numerical simulation of strength, deformation, and failure characteristics of rock with fissure hole defect," Advances in Materials Science and Engineering, vol. 2020, Article ID 7048645, 15 pages, 2020.

[30] R. H. C. Wong, P. Lin, and C. A. Tang, "Experimental and numerical study on splitting failure of brittle solids containing single pore under uniaxial compression," Mechanics of $\mathrm{Ma}$ terials, vol. 38, no. 1-2, pp. 142-159, 2006.

[31] Y.-H. Huang, S.-Q. Yang, P. G. Ranjith, and J. Zhao, "Strength failure behavior and crack evolution mechanism of granite containing pre-existing non-coplanar holes: experimental study and particle flow modeling," Computers and Geotechnics, vol. 88, pp. 182-198, 2017.

[32] R. H. C. Wong and P. Lin, "Numerical study of stress distribution and crack coalescence mechanisms of a solid containing multiple holes," International Journal of Rock Mechanics and Mining Sciences, vol. 79, pp. 41-54, 2015.

[33] S. Zhang, Y. Li, B. Shen, X. Sun, and L. Gao, "Effective evaluation of pressure relief drilling for reducing rock bursts and its application in underground coal mines," International Journal of Rock Mechanics and Mining Sciences, vol. 114, pp. 7-16, 2019.
[34] D. Y. Li, Q. Q. Zhu, and X. B. Li, "Research on the effect of cavity shapes for the progressive failure and mechanical behavior of marble," Chinese Journal of Underground Space and Engineering, vol. 14, no. 1, pp. 58-66, 2018.

[35] Q. Zhu, D. Li, Z. Han, X. Li, and Z. Zhou, "Mechanical properties and fracture evolution of sandstone specimens containing different inclusions under uniaxial compression," International Journal of Rock Mechanics and Mining Sciences, vol. 115, pp. 33-47, 2019.

[36] J. Colleen, M. Mary, and H. Nick, "Strength, deformation modulus and failure modes of cubic analog specimens representing macroporous rock," International Journal of Rock Mechanics and Mining Sciences, vol. 47, pp. 1349-1356, 2010.

[37] Z. Zhou, L. Tan, W. Cao, Z. Zhou, and X. Cai, "Fracture evolution and failure behaviour of marble specimens containing rectangular cavities under uniaxial loading," Engineering Fracture Mechanics, vol. 184, pp. 183-201, 2017.

[38] S. J. Chen, Z. G. Xia, F. Feng, and D. W. Yin, "Numerical study on strength and failure characteristics of rock samples with different hole defects," Bulletin of Engineering Geology and the Environment, vol. 2020, 2020.

[39] Z. G. Xia, S. J. Chen, X. Z. Liu, and R. Sun, "Strength characteristics and fracture evolution of rock with different shapes inclusions based on particle flow code," Geomechanics and Engineering, vol. 22, no. 5, pp. 461-473, 2020.

[40] S. Chen, Z. Xia, F. Feng, and D. Yin, "Numerical study on strength and failure characteristics of rock samples with different hole defects," Bulletin of Engineering Geology and the Environment, vol. 2020, 2020.

[41] C. J. Li, X. B. Li, and D. Y. Li, "Particle flow analysis of fracture characteristics of marble with a single hole," Chinese Journal of Engineering, vol. 39, no. 12, pp. 1791-1801, 2017.

[42] F. Feng, S. J. Chen, D. Y. Li, S. T. Hu, W. P. Huang, and B. Li, "Analysis of fractures of a hard rock specimen via unloading of central hole with different sectional shapes," Energy Science \& Engineering, vol. 7, pp. 1-22, 2019.

[43] P. J. Raymond and H. E. Herbert, "Experimental study of the cracking behavior of specimens containing inclusions (under uniaxial compression)," International Journal of Fracture, vol. 164, pp. 83-102, 2010.

[44] Y. L. Gui, Z. Y. Zhao, C. Zhang, and S. Q. Ma, "Numerical investigation of the opening effect on the mechanical behaviours in rocks under uniaxial loading using hybrid continuum-discrete element method," Computers and Geotechnics, vol. 90, pp. 55-72, 2017.

[45] P. A. Cundall and O. D. L. Strack, "A discrete numerical model for granular assemblies," Géotechnique, vol. 29, no. 1, pp. 47-65, 1979.

[46] N. Cho, C. D. Martin, and D. C. Sego, "A clumped particle model for rock," International Journal of Rock Mechanics and Mining Sciences, vol. 44, no. 7, pp. 997-1010, 2007.

[47] A. Lisjak and G. Grasselli, "A review of discrete modeling techniques for fracturing processes in discontinuous rock masses," Journal of Rock Mechanics and Geotechnical Engineering, vol. 6, no. 4, pp. 301-314, 2014.

[48] J. Wei, Z. Zhao, C. Xu, and Q. Wen, "Numerical investigation of landslide kinetics for the recent Mabian landslide (Sichuan, China)," Landslides, vol. 16, no. 11, pp. 2287-2298, 2019.

[49] X. Wang, Z.-j. Wen, and Y.-j. Jiang, "Time-space effect of stress field and damage evolution law of compressed coalrock," Geotechnical and Geological Engineering, vol. 34, no. 6, pp. 1933-1940, 2016. 
[50] E. G. Kirsch, "Die Theorie der Elasitzität und die Bedürfnisse der Festigkeitslehre," Zantralblatt Verlin Deutscher Ingenieure, vol. 42, pp. 797-807, 1898.

[51] D. Li, Q. Zhu, Z. Zhou, X. Li, and P. G. Ranjith, "Fracture analysis of marble specimens with a hole under uniaxial compression by digital image correlation," Engineering Fracture Mechanics, vol. 183, pp. 109-124, 2017. 